\title{
Product information on freight emissions for consumers : changing the market towards sustainability
}

\section{Sankari, Suvi Elina}

Edward Elgar

2019

Sankari , S E 2019 , Product information on freight emissions for consumers : changing the market towards sustainability . in E Eftestöl-Wilhelmsson, S Sankari \& A Bask (eds), Sustainable and Efficient Transport : Incentives for Promoting a Green Transport Market . , 11 , Edward Elgar , pp. 212-228 . https://doi.org/10.4337/9781788119283.00022

http://hdl.handle.net/10138/312544

https://doi.org/10.4337/9781788119283.00022

unspecified

acceptedVersion

Downloaded from Helda, University of Helsinki institutional repository.

This is an electronic reprint of the original article.

This reprint may differ from the original in pagination and typographic detail.

Please cite the original version. 


\title{
Chapter 11
}

\section{Product information on freight emissions for consumers - changing the market towards sustainability}

\author{
Suvi Sankari*
}

\section{Introduction}

Although the majority of consumers may be guided by price rationality, according to marketing research, at least a segment of green consumers exists. ${ }^{1}$ Others might as well be willing to integrate sustainability into their decision making as one variable. The problem is that consumers have inadequate information to do what the European Commission (Commission) suggests: to lead market-led change by making more sustainable choices. Lack of information is especially a problem as it comes to transport emissions of global value chains (GVCs) that produce consumer goods. At least since the Commission introduced the Integrated Product Policy (IPP) in 2001, freight transport that goes into making (and distributing) products has been considered relevant from the point of view of product life cycle analysis, where it should be integrated as forming part of the product's true environmental costs. ${ }^{2}$ Nevertheless, freight transport - the focus of this chapter - has been explicitly excluded from the scope of European Union (EU) measures that have thus far been introduced to make products ecologically sounder. ${ }^{3}$ Product life cycle analyses have not made their way into the everyday realm of consumers making transactional decisions and whether or not such analyses encompass all freight transport emissions along the GVC remains unclear. Even heavy-duty vehicles (HDVs) have long been unregulated within the EU - unlike in Japan, the United States and Canada - with regard to emissions. ${ }^{4}$

\footnotetext{
${ }^{*}$ Adjunct Professor of European Law, Academy of Finland Postdoctoral Researcher, University of Helsinki, Finland.

${ }^{1}$ More precisely, the size of the segment is 35 per cent of consumers, who tend to be highly educated with high income, according to Arminda M Finisterra do Paço, Mário Lino Barata Raposo and Walter Leal Filho, 'Identifying the green consumer: A segmentation study' (2009) 1 Journal of Targeting, Measurement and Analysis for Marketing 17-25, 23. An 'attitude—behaviour gap' or 'values—action gap' may mean the segment size does not amount to equal actual purchases, see William Young and others, 'Sustainable Consumption: Green Consumer Behaviour when Purchasing Products' (2010) 18 Sustainable Development 20.

${ }^{2}$ Commission, 'Green paper on integrated product policy' (Green Paper) COM(2001) 68 final, 11. In addition to the latest circular economy package (Commission, 'Closing the loop - An EU action plan for the circular economy' (Communication) $(\mathrm{COM}(2015) 614$ final)), there have been several Commissions' initiatives as to 'greening' the internal market since the 2001 Green Paper, prior to and after UN Rio 2012, for example, Commission, 'Roadmap to a Resource Efficient Europe' (Communication) COM(2011) 571 final and Commission, 'Building the Single Market for Green Products Facilitating Better Information on the Environmental Performance of Products and Organisations' (Communication) COM(2013) 196 final.

${ }^{3}$ More on EU measures below. Some emissions-related aspects of transport are internationally regulated, such as fuel content in maritime shipping by the International Maritime Organisation (IMO).

${ }^{4}$ New EU legislation on determining and declaring $\mathrm{CO}_{2}$ emissions and fuel consumption standards for new $\mathrm{HDV}$ sill become applicable from 1 January 2019: Commission Regulation (EU) 2017/2400 of 12 December 2017 implementing Regulation (EC) No 595/2009 of the European Parliament and of the Council as regards the determination of the $\mathrm{CO}_{2}$
} 
Transport services form an integral part of GVCs, and not merely in the sense often perceived: intercontinental container transportation as maritime freight. A definition of GVCs, used for example by the Commission, ${ }^{5}$ is: 'the full range of activities that firms and workers do to bring a product/good or service from its conception to its end use and beyond. This includes activities such as design, production, marketing, distribution and support to the final consumer'. ${ }^{6}$ The GVC definition does not explicitly mention freight transport - it omits many issues the EU law regulates (passenger transport, physical composition of products and waste handling) - yet transport is clearly part of the full range of activities referred to in the definition. The role of transport is acknowledged by both Commission policy as well as its research funding; however, it has thus far been ignored by the EU legislator.

Something that goes even further than GVCs in omitting the role of freight transport emissions is the Commission's recent circular economy package of $2015 .^{7}$ In its ongoing quest to transform the economy from linear to circular, where value is maintained as long as possible and waste recycled into raw materials as much as possible, the Commission continues to emphasize the importance of market-led change, which should be facilitated by helping consumers choose sustainable products and services. Two issues arise: (1) Has the role of circular economy in increasing freight transport emissions been considered? and (2) Is enough information (including freight transport emissions) available to the consumer to make more informed sustainable choices? The first question serves to frame the discussion because answering it escapes the scope of this chapter. On the basis that relevant Commission documents do not address freight transport, it can be assumed that its emissions have not been integrated into the Commission's vision of circular EU economy. This has a lot to do with the answer to the second question, on which this chapter focuses. If consumers lack integrated information, or information overall, on freight transport emissions generated in manufacturing the products they are offered, then consumers cannot factor these in when they make market choices. If freight transport emissions are side-lined and only lightly regulated indirectly, if at all, then there are no market-led or regulative incentives for the freight transport industry (forming an integral part of GVCs) to become more sustainable.

Setting aside some voluntary standards and national regulations, the aspect of products (and services) that relates to their transport emissions has not been regulated internationally or by the EU. This has resulted in the transport industry and, in turn, those who produce industrial products in GVCs possibly not caring

emissions and fuel consumption of HDVs and amending Directive 2007/46/EC of the European Parliament and of the Council and Commission Regulation (EU) No 582/2011 [2017] OJ L349/1. See also Commission, 'Strategy for Reducing Heavy-Duty Vehicles' Fuel Consumption and $\mathrm{CO}_{2}$ Emissions' (Communication) COM(2014) 285 final, 2. ${ }^{5}$ Commission, 'Sustainable garment value chains through EU development action' (Staff Working Document) SWD(2017) 147 final, 5, according to which, 'the notions value chain and supply chain can be used interchangeably as in the EU Council conclusions of 12 May 2016'. For more, see United Nations Conference on Trade and Development (UNCTAD), 'World Investment Report 2013, Global Value Chains: Investment and Trade for Development' (New York and Geneva: United Nations, 2013), <http://unctad.org/en/PublicationsLibrary/wir2013_en.pdf>, accessed 5 May 2018.

${ }^{6}$ See <www.globalvaluechains.org/concept-tools>, accessed 5 May 2018.

${ }^{7} \operatorname{COM}(2015) 614$ final (n 2). 
about freight transport emissions and certainly not communicating specific freight transport-related information to product consumers (private and professional). Information asymmetries may generally have contributed to the lack of market demand for disclosing information on freight transport emissions. ${ }^{8}$

\section{Practical example}

Typically, for example in garments, the GVCs have become longer as well as more dispersed geographically, increasing the distances that intermediate as well as final products travel on different modes of transport. Trade within GVCs accounts for 80 per cent of total world trade. ${ }^{9}$ In turn, according to some estimates, the 10 per cent share of transport related to international trade that takes place domestically ('domestic leg', typically relying on road haulage) generates 30 per cent of trade-related carbon dioxide $\left(\mathrm{CO}_{2}\right)$ emissions. ${ }^{10}$ Hence, the emissions produced by 'before-port' and 'after-port' road haulage of goods, typically by HDVs, are the source of a disproportionate share of transport-related $\mathrm{CO}_{2}$ emissions, a type of emissions that is generally on the rise. ${ }^{11}$ Road haulage as a source of emissions concerns both products produced in GVCs as well as products that are produced and bought within the EU internal market ('products of VCs'), and information on transport emissions of neither is available to the consumer. The consumer expected to make more sustainable choices on the market is unaware of whether, in general, overseas transport fleet and infrastructure ('domestic leg of origin') fare worse in terms of emissions than in the EU on average ('domestic leg of destination, or origin and destination'), or, specifically, how products of different GVCs fare against each other or against products of VCs in this respect. Hence, including this aspect into distinguishing between products' sustainability is largely impossible for the consumer. This in turn excludes any market signals based on such comparisons that could have potential to affect transportation and production patterns.

Goods-producing companies with wide-reaching GVCs are aware of the disproportionate share of emissions created by road haulage, and some wish to project the image that they are doing something about it. Furthermore, companies choose to provide information on greenhouse gas (GHG) emissions to their investors and clients (consumers). Because this information is based on applying private standards chosen by the (GVC lead) companies themselves instead of harmonized mandatory law, it is relatively obsolete in

\footnotetext{
${ }^{8}$ Lack of information is, in turn, related to the lack of push for intermodal transport that should be environmentally friendlier than, for example, road haulage, alone. See also Anu Bask and Mervi Rajahonka, 'The role of environmental sustainability in the freight transport mode choice: A systematic literature review with focus on the EU' (2017) 47(7) International Journal of Physical Distribution \& Logistics Management 560; Chapter 4 Maria Munõs-Torres et al.) ${ }^{9}$ According to United Nations Conference on Trade Development (UNCTAD) World Investment Report 2013 (n 5) x, global supply chains of transnational corporations account for 80 per cent of all world trade.

${ }^{10}$ OECD International Transport Forum, 'The Carbon Footprint of Global Trade' (OECD/ITF, 2015) <https://www.itfoecd.org/carbon-footprint-global-trade> accessed 29 October 2018, 9. The concentration of emissions is explained by the fact that road HDVs may continue to escape fuel-economy standards, the typical focus point in emissions reduction. ${ }^{11}$ See Preface to this edited volume; Chapter 8 Ellen Eftestöl-Wilhelmsson)
} 
terms of consumers comparing different products on the market. To give a practical illustration, the large apparel manufacturer and retailer Inditex ${ }^{12}$ reports having concentrated its production in southern Spain, close to its logistics centres and head office, to cut travel distances. ${ }^{13}$ However, Inditex is presumably referring only to its own production in Spain when stating that ' $[\mathrm{m}]$ ost production is also carried out in proximity'. ${ }^{14}$ The company has 10 logistics centres and 11 factories in Spain and claims that '59 per cent of the factories we work with are in proximity to our headquarters, mainly in Spain, Portugal, Turkey and Morocco'. ${ }^{15}$ However, in 2015 Inditex reported having 171 suppliers in the EU outside Spain and a further 951 suppliers outside the EU - for example in India, Bangladesh and China - with a total of 2777 sewing factories linked to these non-EU suppliers (instead of directly linked to Inditex). ${ }^{16}$ In 2016 the total number of suppliers reportedly rose to $1805 .^{17}$

A consumer devoted to finding information on $\mathrm{CO}_{2}$ emissions of Inditex garments and disposed to spending time roaming the company's website to review its Environmental Indicators ultimately would discover in the 'sustainability balance sheet' that $\mathrm{CO}_{2}$ emissions per garment released on the market ${ }^{18}$ has gone down to 405.83 in 2016 from 548.38 in 2015 and that number '[i]ncludes emissions scopes 1 and 2'. ${ }^{19}$ This classification seems to suggest that Inditex uses the voluntary and private GHG Protocol Corporate Standard (GHGPCS) $)^{20}$ for reporting emissions in its sustainability balance sheet. This information, 405.83 $\mathrm{CO}_{2}$ per garment, nowhere to be found on garment labels (via barcode scan) in stores or in product details provided when shopping online, tells the consumer fairly little.

Even if the information on $\mathrm{CO}_{2}$ emissions per garment were to reach the consumer, its accuracy or inclusiveness as to covering the entire GVC can be questioned. ${ }^{21}$ For example, the GHGPCS methodology

\footnotetext{
12 The example here is neither based on a comprehensive or even representative sampling of companies nor rankings based on private standards (for example, on the Fashion Transparency Index 2018 Inditex brands score 5/10, when highest scores reported overall are 6/10, see Sarah Ditty, 'Fashion Transparency Index 2018' (Fashion Revolution CIC, 2018) <https://issuu.com/fashionrevolution/docs/fr_fashiontransparencyindex2018> accessed 5 May 2018, 26). It is a random choice that assumes Inditex (Industria de Diseno Textil SA) is a reasonably environmentally engaged and transparent (that is, sustainability information available) large European company in the textile sector.

${ }^{13}$ At <https://www.inditex.com/how-we-do-business/our-model/logistics>, accessed 5 May 2018.

14 ibid.

$15 \mathrm{ibid}$, and at https://www.inditex.com/en/how-we-do-business/our-model/products>, accessed 5 May 2018 (italics mine).

${ }^{16}$ At Inditex Annual Report 2015, 'Sustainability Balance Sheet: Social Indicators' (Inditex, 2015) <http://static.inditex.com/annual_report_2015/en/sustainability-balance/sustainability-balance/social-indicators.php>, accessed 5 May 2018.

${ }^{17}$ At Inditex Annual Report 2016, 'Sustainability Balance Sheet: Sustainability Indicators' (Inditex, 2016)

<http://static.inditex.com/annual_report_2016/en/sustainability-balance-sheet/sustainability-indicators/>, accessed 5 May 2018.

${ }^{18}$ The market referred to can be assumed global yet nowhere defined.

${ }^{19}$ Inditex Annual Report 2016 (n 17).

${ }^{20}$ According to the standard, scope 1 refers to direct GHG emissions covered by the Kyoto Protocol that 'occur from sources that are owned or controlled by the company' including, for example, vehicles. Scope 2 'accounts for GHG emissions from the generation of purchased electricity consumed by the company'. Scope 3 includes indirect GHG emissions the sources of which are 'not owned or controlled by the company'. See <http://www.ghgprotocol.org/corporate-standard>, accessed 5 May 2018, and also Chapter 9 Jaakko Salminen. ${ }^{21}$ Whether such a practice could constitute a misleading information or environmental claim, prohibited by the Unfair Commercial Practices Directive (2005/29/EC (n 54)) is a question not examined in detail here. Suffice it to say
} 
allows not reporting transport emissions from sources not owned or controlled by Inditex. More precisely, it is complicated if not impossible for a consumer to understand whether the reported numbers include transport-related emissions upstream (such as emissions from moving materials between suppliers and sewing factories and to the port) and downstream (distribution, ${ }^{22}$ stocking, ${ }^{23}$ repairing or recycling ${ }^{24}$ ) in the GVC. It is also impossible to gauge how much the levels of emissions would generally vary across different, more or less highly regulated, territories where parts of the GVC operate. ${ }^{25}$ Moreover, assuming that neither indicating the origin of products (or that of the parts they comprise) nor traceability is mandatory - like in the EU - this non-transparency further hinders the guesswork about the regulatory environments involved throughout the GVC. Though it ultimately remains unclear, it is relatively safe to assume that, in the case of Inditex, $\mathrm{CO}_{2}$ emissions of overseas suppliers of its GVCs are not reported, and the same may hold for freight transport in general. ${ }^{26}$ As the information is not forwarded to consumers more aggressively, one can also question whether voluntary sustainability reporting is more about company image and fitting particular types of investment portfolios than about affecting consumer choice. ${ }^{27}$

Comparability between clothing manufacturers who use the same standard, the GHGPCS, could offer potential value of this information - the number above - for the consumer (were it readily available). In legal scholarship, end-user incomparability issues as well as general reasons of market fairness are regular

standards, though incomprehensible for consumers, allow for verifying the information and, moreover, no false 'green' or 'environmental' claim (such as 'sustainable' or 'climate friendly') is actually made. For more, see Commission, 'Guidance on the Implementation/Application of Directive 2005/29/EC on Unfair Commercial Practices, accompanying the document Communication from the Commission to the European Parliament, the Council, the European Economic and Social Committee and the Committee of the Regions, 'A comprehensive approach to stimulating cross-border eCommerce for Europe's citizens and businesses' (Staff Working Document) SWD(2016) 163 final, 95ff.

${ }^{22}$ Presumably excluded from the reports are transport emissions from delivering consumer online purchases through courier services as well as transport services stocking Inditex retail outlets. The assumption here is that most courier and freight transport are externally bought services that the precise level of the GHGPCS standard with which Inditex has chosen to comply allows to exist outside its voluntary sustainability accounting (that is, emissions not reported when goods not delivered with Inditex-owned or controlled fleet).

${ }_{23}$ On engaging with emissions from stock distribution (presumably beyond GHGPCS requirements), Inditex (<https://www.inditex.com/how-we-do-business/our-model/logistics>, accessed 5 May 2018) states: 'We have developed a tool to measure emissions based on different means of transportation in line with international standards laid down in the GHG Protocol, so that we can track progress, and we offer improvement plans for our distributors to make reductions'.

${ }^{24}$ For pointing out that extended product lifetime may have negative effects as well, such as environmental impacts of transport for repairs, see Carl Dalhammar and others, 'Addressing resource efficiency through the Ecodesign Directive: A review of opportunities and barriers' (TemaNord 2014:511) <http://norden.diva-

portal.org/smash/get/diva2:710881/FULLTEXT01.pdf> accessed 5 May 2018, 56. Without careful logistics, recycling opportunities for old garments at stores (which Inditex reports to offer), for example, may create further freight transport emissions.

${ }^{25}$ GVC production in countries where emissions-related standards (for example vehicles and fuel) are lower or less environmentally friendly than elsewhere might in turn mean that some unexpectedly high 'hidden' transport-related emissions are included in the product's ecological footprint.

${ }^{26}$ For an illustrative example on DHL as to the effects on reporting different GHGPCS scope (1-3) emissions, see 'The Greenhouse Gas Protocol: A Corporate Accounting and Reporting Standard (Revised Edition) '

<https://ghgprotocol.org/sites/default/files/standards/ghg-protocol-revised.pdf> accessed 5 May 2018, 30.

${ }^{27}$ Critically on the relationship between legal rules on unfair commercial practices and CSR advertising, see Jules Stuyck, 'Corporate Social Responsibility-Standards and the Belgian and French Perspective' in Reto M Hilty and Frauke Henning-Bodewig (eds) Corporate Social Responsibility. MPI Studies on Intellectual Property and Competition Law, vol 21 (Springer 2014), 225. 
arguments for replacing voluntary standards with mandatory laws. The use of different private ('green' product, service or company) standards works here just like it does in so many other contexts as well: ${ }^{28}$ Their incommensurability, or more precisely that of the information they provide, would make informed choice overly difficult for buyers of transport services as well as end products. Be that as it may, companies like Inditex collect vast amounts of information regarding products, production methods and the GVC (including emissions), which they choose to only selectively share with consumers. ${ }^{29}$ This is possible because nothing, such as law, compels them to do otherwise.

Next, we consider how this information asymmetry might be cured through law. However, it should be stated that although freight transport emissions might not be transparently reported, sustainability may still be featured - even prominently - in those services. ${ }^{30}$ Motivated by corporate policy or ('triple') bottomline sustainability supply, presumably an element of demand exists. All major parcel delivery services (DHL, FedEx, DPD, UPS) offer 'green' services to industrial customers. For example, DHL offers a 'GoGreen' programme with 'Green Logistics Solutions', such as carbon reporting. ${ }^{31}$ Presumably, as industrial demand exists, freight logistics and transport service providers also offer green options. Interestingly, though similar green choices in parcel services are available for consumers $(\mathrm{C} 2 \mathrm{C})$ on many markets, when it comes to the delivery of online shopping (B2C), general experience shows that often not even the use of a particular courier is transparent at the point of purchase - and much less the environmental impact of delivery (or increasingly 'free' returns). For reasons that remain unclear, green transport is not currently offered as a selling point or any kind of factor in consumers' online transactional decisions on products. The information required for product-to-product (delivered) comparisons, including transport-related $\mathrm{CO}_{2}$ emissions, is generally not available (for example when purchasing clothes online). Therefore, the choice about green delivery to the consumer is also not available. The present situation does not support the market-led behavioural change of industries endorsed by the Commission - neither on a global nor local level. Regardless of that, plans for direct regulatory intervention have not emerged.

\footnotetext{
${ }^{28}$ The typical market failure problems that standards give rise to are often considered to require intervention by the legislator, see Douglas A Kysar, 'Preferences for processes: The Process/Product Distinction and the Regulation of Consumer Choice' (2004) 118 Harvard Law Review, 526, 626. However, assuming constant technical development, the problem that arises after intervention is that legislating (mandatory standard-setting) is typically a slow process and hence the standards it sets will constantly lag behind technical development. See Carl Dalhammar, 'Promoting Energy and Resource Efficiency through the Ecodesign Directive' (2014) 59 Scandinavian Studies in Law, 147, 176.

${ }^{29}$ Transport-related emissions are not the only undisclosed GVC information. Research suggests that GVC traceability could give rise to traceability systems that link to other existing corporate systems, such as logistics; however, momentarily, companies do not disclose which traceability systems they are using - if any. See Raul Richero and Simon Ferrigno 'A Background Analysis on the Transparency and Traceability in the Garment Value Chain - Final Report' (DAI 2017), 16 and 21, <https://ec.europa.eu/europeaid/sites/devco/files/final_report_04-07-2017.pdf>, accessed 5 May 2018, and also Vijay Kumar, Carina Hallqvist and Daniel Ekwall, 'Developing a Framework for Traceability Implementation in the Textile Supply Chain' (2017) 5(2) Systems, 33.

${ }^{30}$ See Chapter 9 Jaakko Salminen.

31 'Calculation adheres to EN 16258 "Methodology for calculation and declaration of energy consumption and GHG emissions of transport services"”, see <http://www.dhl.fi/en/logistics/green_logistics_solutions.html>, accessed 5 May 2018.
} 
In summary, emissions of transport services that feed into and sustain $(\mathrm{G}) \mathrm{VCs}$ must form a significant part of the ecological footprint of products. As illustrated by the practical example here, it seems a relatively small part (10 per cent) of transport in GVCs emits an excessive proportion (30 per cent) of the entire trade-related $\mathrm{CO}_{2}$ emissions (70 per cent) in the world. ${ }^{32}$ The emissions of the 'domestic leg' - in GVCs there are typically two domestic legs, pre- and post-port - are presumably not meaningfully reported to public authorities, shareholders or consumers and, hence, do not feature in anyone's (transactional) decisions.

\section{Cause for regulation?}

Very little has been done by way of regulation, or even voluntary standards, to highlight intrinsic-to(G)VC transport emissions by making them visible to and comparable for the product end users. As the market is today, GVC freight transport emissions seem to be at least partly unpriced and unregulated negative externalities, or competitive advantages, depending on the point of view. As opposed to passenger transport or consumer parcel services, in the freight transport market a possible market demand for emissions disclosure arising from end consumers - which in turn would generate market-led change - seems excluded because of lack of information and hence lack of demand. Unless the nudge towards change arises out of green investor policies, industry seems to lack incentives as GVC emissions should be reduced for the sake of reducing emissions alone. Therefore, to affect change, legislators could consider intervening in the market; in other words, a cause for regulating may exist.

Turning to the existing legal framework, with an eye on cause for further regulation, this chapter proceeds as follows: first, the state of 'pre-law' (standards, soft law) is examined; second, the existing framework for indirect regulation of freight transport emissions in the EU is outlined; and third, the focus is shifted to sketching a viable alternative to non-regulation by drawing analogically on certain product regulation.

\footnotetext{
${ }^{32}$ OECD International Transport Forum (n 10), 9.
} 


\subsection{Role of law?}

\subsubsection{Voluntary standards, soft law - reporting duties?}

At the outset of the 2010s, Islam and Zunder identified 13 European standards specifically on transport and logistics and another three international standards, which in practice are relevant for transport and logistics though not specifically aimed at the transport and logistics industry. ${ }^{33}$ In 2012 the European Committee for Standardisation (CEN) introduced a European standard called CEN 16258 on 'methodology for calculation and declaration of energy consumption and GHG emissions of transport services (freight and passengers)'. The CEN 16258 is a European reporting standard, ${ }^{34}$ the use of which is voluntary. Based on information gathered through consulting with industry actors and stakeholders, using methods including interviews and Delphi studies, ${ }^{35}$ Islam and Zunder concluded that 'European international [CEN] standards for freight transport and logistics quality are known to few users', but 'ISO 9001 and ISO 140001 are capable of managing quality and are used as such'. Furthermore, according to the industry '[q]uality is better determined by a contract between customer and provider, not for the whole supply chain' ${ }^{36}$

CEN 16258 directly relates to transport services. However, it does not specify how the information gathered according to this methodology can or should be communicated to, for example, end users of transported consumer products. Nevertheless, the standard has found its way to becoming part of hard law in national French legislation (Transport Code, Article L. 1431-3; Decree no. 2011-1336 of 24 October 2011). ${ }^{37}$ The French Transport Code has made disclosure of $\mathrm{CO}_{2}$ emissions mandatory for all transport services since October 2013 and relies on the CEN 16258 standard. Though any calculation methodology, or the leeway the concepts involved allow for, is open to criticism, choosing one standard presumably produces more comparable information for the French consumer than would be available without designating CEN 16258 as the shared standard. Hence, regulative intervention would produce comparable, although equally imperfect, information on the alternatives available for the consumer.

The role of information in consumers making more sustainable transactional choices, purchasing 'green products', is more important than is often thought, according to some initial marketing research. For

\footnotetext{
${ }^{33}$ Dewan Md Zahurul Islam and Thomas H Zunder, 'The Necessity for a New Quality Standard for Freight Transport and Logistics in Europe' (2014) 6(4) European Transport Research Review 397, 402.

${ }^{34}$ Voluntary standards can be divided into certification standards, reporting standards and process standards, see Andreas Rasche, 'Voluntary standards as enablers and impediments to sustainable consumption' in Lucia A Reisch and John Thøgersen (eds), Handbook of Research on Sustainable Consumption (Edward Elgar 2015) 343, 347.

${ }^{35}$ Interviews and Delphi studies conducted presumably around 2010-2011 - no specific date is found but research coincides with Commission funding under FP7 for research project 'BE LOGIC: Benchmarking Logistics Chains'.

${ }^{36}$ Islam and Zunder (n 36), 407.

${ }^{37}$ L'article L. 1431-3 du code des transports, issu de l'article 228 de la loi n ${ }^{\circ} 2010-788$ du 12 juillet 2010 (<http://www.legifrance.gouv.fr>, accessed 5 May 2018), see also Décret n² 2011-1336 du 24 octobre 2011 relatif à l'information sur la quantité de dioxyde de carbone émise à l'occasion d'une prestation de transport.
} 
example, Gleim et al. found their 'results suggest that the slight amount of information presented on green product packaging may not have a positive impact on consumers, as detailed verbal cues are preferred' ${ }^{38}$ Lack of both information and feeling of expertise are recognized as significant barriers for green consumption, in addition to price. ${ }^{39}$ However, literature suggests that all consumers are 'green' in the sense that if choosing between two otherwise identical products, almost all would pick the green one. ${ }^{40}$ Hence, one can speculate that should freight transport-related emissions differentiate two otherwise similar products from each other and the consumer had sufficient information of this, the consumer would apply this criterion to distinguish between products and would purchase the more sustainable one. In other words, regulative intervention making transport emissions information disclosure mandatory would offer the consumer this choice.

The non-binding Commission guidelines on how large companies (over 500 employees) must, from 2017 onwards, report non-financial information - required by an amendment Directive ${ }^{41}$ from 2014 suggest companies should consider reporting the 'environmental impacts from transportation' as well as GHG emissions of their supply chain as key performance indicators. ${ }^{42}$ What the amended Directive requires is that companies report a review of their policies (or non-policies), principal risks and outcomes on environmental issues among others. The Directive, which the Member States implement, leaves relatively open both the methods for gathering information as well as where and how it is reported. The use of certain guidelines or methods is recommended but not obligatory. ${ }^{43}$ Hence, the reports will not follow a similar format and the information in them will not be readily comparable across companies even in the same sector. What is more, the information required by the Directive will not be reported on product labels for the consumer when shopping.

\footnotetext{
${ }^{38}$ Mark R Gleim and others, 'Against the Green: A Multi-method Examination of the Barriers to Green Consumption' (2013) 89(1) Journal of Retailing 44, 57-58.

${ }^{39}$ ibid.

${ }^{40}$ Originally, W J Kardash, 'Corporate Responsibility and the Quality of Life: Developing the Ecologically Concerned Consumer' in Henion and Kinner (eds) Ecological Marketing (American Marketing Association 1974).

${ }^{41}$ Directive 2014/95/EU of the European Parliament and of the Council of 22 October 2014 amending Directive 2013/34/EU as regards disclosure of non-financial and diversity information by certain large undertakings and groups [2014] OJ L330/1.

${ }^{42}$ Commission, 'Guidelines on non-financial reporting (methodology for reporting non-financial information)', (Communication) 2017/C 215/01, 15.

${ }^{43}$ For instance, using national, European or international guidelines (UN Global Compact) is encouraged, and the Commission guidelines refer to methods specified in Commission Recommendation 2013/179/EU of 9 April 2013 on the use of common methods to measure and communicate the lifecycle environmental performance of products and organisations [2013] OJ L124/1 annexes, which include Product Environmental Footprint and Organisation Environmental Footprint.
} 


\subsubsection{Regulating indirectly}

The way in which freight transport emissions are regulated within the EU territory is indirect, through regulation of some vehicles, tyres, speed and fuel or energy used ${ }^{44}$ or, for example, through regulating public procurement and public services in transport. ${ }^{45}$ Certain regulative options have not been exercised. Methodological difficulties have prevented including emissions from transport into life cycle analyses of products. ${ }^{46}$ As far as indications of origin on product labels could imply, the distance travelled and the regime under which one domestic leg of emissions is produced, mandatory disclosure of country of origin to the consumer is traditionally considered contrary to EU law and a suspect category of measures under World Trade Organisation (WTO) law. ${ }^{47}$ Whereas many indirectly related legal aspects have an impact on GVC design ${ }^{48}$ there seem to be no industry practices nor laws that would ensure transport emissions feature as parameters in GVC design. When it comes to transport emissions in (G)VCs, curbing them relies on more strict or lax domestic regulation as well as on simple efficiency gains in that it presumably is bad business - from the point of view of transport $\operatorname{costs}^{49}$ - to transport goods for longer distances than necessary and/or to use inefficient (polluting) means (vehicles and logistics).

\footnotetext{
${ }^{44}$ For passenger cars and light commercial vehicles, both vehicle emissions and consumer information duties are regulated (Regulation (EC) No 715/2007 of the European Parliament and of the Council of 20 June 2007 on type approval of motor vehicles with respect to emissions from light passenger and commercial vehicles (Euro 5 and Euro 6 ) and on access to vehicle repair and maintenance information [2007] OJ L171/1); Directive 1999/94/EC of the European Parliament and of the Council of 13 December 1999 relating to the availability of consumer information on fuel economy and $\mathrm{CO}_{2}$ emissions in respect of the marketing of new passenger cars [1999] OJ L12/16; Regulation (EU) No 510/2011 of the European Parliament and of the Council of 11 May 2011 setting emission performance standards for new light commercial vehicles as part of the Union's integrated approach to reduce $\mathrm{CO}_{2}$ emissions from light-duty vehicles [2011] OJ L145/1) and for new HDVs (n 4). Safety of motor vehicles and the environmental performance of tyres are regulated in the 'General Safety Regulation' (Regulation (EC) No 661/2009 of the European Parliament and of the Council of 13 July 2009 concerning type-approval requirements for the general safety of motor vehicles, their trailers and systems, components and separate technical units [2009] OJ L200/1, 31.7.2009.

${ }^{45}$ See, for example, Directive 2009/33/EC of the European Parliament and of the Council of 23 April 2009 on the promotion of clean and energy efficient road transport vehicles [2009] OJ L120/5.

${ }^{46}$ See (n 42).

47 On EU law, see, for example, Lawrence W Gormley, EU Law of Free Movement of Goods and Customs Union (OUP 2009), 430, citing Case 207/83 Commission v United Kingdom [1985] EU:C:1985:161, 1212. As to WTO law, different opinions exist on whether non-product related processes and production methods (PPMs) are prohibited: Steve Charnovitz, 'The Law of Environmental PPMs in the WTO: Debunking the Myth of Illegality' (2002) 27(1) Yale Journal of International Law 59.; Jagdish Bhagwati and Petros C Mavroidis, 'Is action against US exports for failure to sign the Kyoto Protocol WTO legal?' (2007) 6(2) World Trade Review, 299; Gracia Marín Durán, 'NTBs and the WTO Agreement on Technical Barriers to Trade: The Case of PPM-Based Measures Following US - Tuna II and EC - Seal Products' in Christoph Herrmann, Markus Krajewski and Jörg P Terhechte (eds) European Yearbook of International Economic Law (Springer-Verlag, Berlin Heidelberg 2015).

${ }^{48}$ Dan Danielsen and others, 'The role of law in global value chains: a research manifesto' (2016) 4(1) London Review of International Law 57.

${ }^{49}$ For example, Kathryn Joseph, Timothy O’Brien and Henrique Correa ('Tax strategies and organisational communication in MNC supply chains: case studies' (2016) 20(2) International Journal of Logistics: Research and Applications 105, 119) find that: "none of the three companies studied ... - ...had calculated the relative tax savings versus S[upply] C[hain] costs of their tax strategy.' Similarly, see Oskar Henkow and Andreas Norrman, 'Tax Aligned Global Supply Chains' (2011) 41(9) International Journal of Distribution \& Logistics Management, 878.
} 
With a bit of legal science fiction, one argument for further regulation could be that such EU law already exists on which consumers could rely as to right to information. Assuming such omitted information - freight transport-related emissions in (G)VCs or supply chains - affects (average) consumers' transactional decisions on products or services and is considered material information on what is being purchased, a trader not disclosing this information would be breaching the rights granted to consumers by the Unfair Commercial Practices Directive. ${ }^{50}$ Although the Directive textually allows for such an alternative interpretation, opting for it must be considered unlikely in practice. ${ }^{51}$ One reason for mandatory disclosure would be that, like Inditex in our example, companies presumably hold ample information on their own emissions as well as on those of their overseas suppliers and the transport services they use, but they do not disclose them currently. The cost of disclosure should not be prohibitively high. Another point for disclosure would be the French example mentioned above, which seems to be treating emissions disclosure as material information - though not for reasons of consumer protection but (national) climate strategy instead. One point against disclosure was also mentioned above - the incommensurability of information relying of different standards and methodologies.

\subsubsection{Direct regulations - analogy from existing product regulations?}

The potential of different EU instruments to reduce emissions is difficult to grasp without setting them on some sort of relative scale. Therefore, a parallel to existing regulation is made next. The Ecodesign Directive $^{52}$ is a framework directive that facilitates regulating energy-related aspects of products by serving as the basis for product-group-specific delegated acts. ${ }^{53}$ The acts set product-group-specific efficiency values that in turn have been determined with the help of product life cycle assessment methodology (which, for example, does not integrate transport as part of the life cycle of a product). ${ }^{54}$ The Ecodesign Directive also allows setting some generic requirements, which typically concern informing consumers of contents or use of a product. The Ecodesign Directive is distinct from energy labelling, waste and hazardous substances

\footnotetext{
${ }^{50}$ Cf. Art. 7 of Directive 2005/29/EC of the European Parliament and of the Council of 11 May 2005 concerning unfair business-to-consumer commercial practices in the internal market and amending Council Directive 84/450/EEC, Directives 97/7/EC, 98/27/EC and 2002/65/EC of the European Parliament and of the Council and Regulation (EC) No 2006/2004 of the European Parliament and of the Council ('Unfair Commercial Practices Directive') [2005] OJ L149/22 on the trader's duty to disclose material information on the product required for the 'average consumer' to take a 'transactional decision' on products and services. See also Geraint Howells, Hans-Wolfgang Micklitz and Thomas Wilhelmsson, European Fair Trading Law (Ashgate 2006), especially 141ff.

${ }^{51}$ See also Case C-632/16 Dyson Ltd v BSH Home Appliances NV [2018] EU:C:2018:599.

${ }^{52}$ Directive 2009/125/EC of the European Parliament and of the Council of 21 October 2009 establishing a framework for the setting of ecodesign requirements for energy-related products OJ L285/10.

${ }^{53}$ There are altogether 34 ecodesigns implementing regulations (as of 3 May 2018) that mainly concern large household appliances and that tend to be either product-specific (such as household washing machines or televisions) or partspecific (such as power transformers) or general categories of products (such as lighting products) and three (as of 20 December 2016) voluntary agreements (that is, industry self-regulation) that the Commission has 'recognized'.

${ }^{54}$ For a critical analysis on MEErP (Methodology for Ecodesign of Energy-using Products) methodology and other limitations of the Ecodesign Directive, see Dalhammar (n 28), 174.
} 
regulation concerning products ${ }^{55}$ and more horizontal regulations on product safety and chemicals. ${ }^{56}$ Article 1(3) of the Ecodesign Directive ${ }^{57}$ explicitly excludes 'means of transport for persons or goods' from its scope.

According to some early evaluations, from 2020 onward the effects of the Ecodesign Directive are expected to include reduced GHG emissions $\left(\mathrm{CO}_{2}\right)$ similar in size to the EU Emissions Trading Scheme (ETS) system, which altogether is expected to reduce 400 Mtonnes of $\mathrm{CO}_{2}$ annually by $2020 .^{58}$ A 2016 Commission-ordered impact assessment reported expected results of the Ecodesign Directive for the EU-28 in 2020 - an estimated 7 per cent decrease in GHG emissions and 9 per cent in energy consumption from the EU 2010 total. ${ }^{59}$ No estimate as to the effects of the Directive on costliness or inefficiency of the instrument or the decrease in innovation, competitiveness or jobs were presented, ${ }^{60}$ and the two different estimates of the Directive's emissions mitigation are not straightforward to compare. The weightier aspect driving the Ecodesign Directive's success in decreasing emissions is definitely that it sets requirements for products' energy efficiency during use - an idea aligned with, for example, EU legislation on fuel efficiency of HDVs; nevertheless, the informational element it includes (for example, how to use a given product energy efficiently) may also have brought some cost-efficient added value.

Mentioning the Ecodesign Directive and comparing it to the ETS is used here for making an argument for the positive potential of (cost-efficient) behaviourally aligned instruments that rely on offering information aimed at affecting behaviour while preserving freedom of choice. An even better justification for introducing an EU instrument requiring the disclosure of transport-related emissions of products might be the already behaviourally tested French Transport Code requiring mandatory disclosure of $\mathrm{CO}_{2}$ emissions of transport services - in case it has turned out to be effective. Whereas the Ecodesign Directive has been determined a successful instrument at reducing emissions and its (future) effects are at least estimated, the

\footnotetext{
${ }^{55}$ Regulation (EU) 2017/1369 of the European Parliament and of the Council of 4 July 2017 setting a framework for energy labelling and repealing Directive 2010/30/EU [2017] OJ L198/1; Directive 2012/19/EU of the European Parliament and of the Council of 4 July 2012 on waste electrical and electronic equipment [2012] OJ L197/38 - that is, the WEEE Directive; and Directive 2011/65/EU of the European Parliament and of the Council of 8 June 2011 on the restriction of the use of certain hazardous substances in electrical and electronic equipment [2011] OJ L174/88 - that is, the 'RoHS' Directive.

${ }^{56}$ Directive 2001/95/EC of the European Parliament and of the Council of 3 December 2001 on general product safety [2001] OJ L11/4 - the 'Product Safety Directive'; Regulation (EC) No 1907/2006 of the European parliament and of the Council concerning the Registration, Evaluation, Authorisation and Restriction of Chemicals (REACH), establishing a European Chemicals Agency, amending Directive 1999/45/EC and repealing Council Regulation (EEC) No 793/93 and Commission Regulation (EC) No 1488/94 as well as Council Directive 76/769/EEC and Commission Directives 91/155/EEC, 93/67/EEC, 93/105/EC and 2000/21/EC [2006] OJ L396/1 - the 'REACH' Directive.

${ }^{57}$ Directive 2009/125/EC (n 52).

${ }^{58}$ Edith Molenbroek, Maarten Cuijpers and Kornelis Blok, 'Economic benefits of the EU Ecodesign Directive: Improving European economies' (ECOFYS Report, 2012) <https://www.ecofys.com/files/files/ecofys_2012_economic_benefits_ecodesign.pdf $>$, accessed 5 May 2018, 5.

${ }^{59}$ René Kemna, Leo Wierda and Sanne Aarts, 'Ecodesign Impacts Accounting, Status Report September 2016' ((Van Holsteijn en Kemna B.V. (VHK), 2016) <https://ec.europa.eu/energy/en/studies/ecodesign-impact-accounting-0> accessed 29 October 2018, 6.

${ }^{60}$ Beate Sjåfell and Benjamin J Richardson, 'Capitalism, the Sustainability Crisis, and the Limitations of Current Business Governance' in Beate Sjåfell and Benjamin J Richardson (eds) Company Law and Sustainability: Legal Barriers and Opportunities (CUP 2014), $15 \mathrm{fn} 65$.
} 
information required for assessing the actual effects of the French Code was not available at the time of writing.

\section{Concluding discussion}

Technological progress has already allowed easy access to real-time information of various aspects of the $(\mathrm{G}) \mathrm{VC}$ and will soon allow measuring and verifying actual transport-related emissions with accuracy. For marketing or other reporting purposes, companies disclose some information on their GHG emissions, including or not including freight transport. At best, such information is varied and incommensurable; at worst, it is misleading greenwashing. Hence, it is time to introduce an EU legislative instrument that sets a duty on producers and retailers of products to disclose more information in a harmonized manner on the EU internal market. ${ }^{61}$

The information could be provided on product labels or as additional recoverable information via scanning barcodes, QR codes, or the like. In line with the Ecodesign Directive, the required regulative instruments could either be outcomes of the legislative process or industry agreements. Like with the Ecodesign Directive, the approach could be incremental - the information requirements could increase at a certain transparently set pace. The required information could concern emissions including transport along the entire product life cycle, integrated information encompassing the product $(\mathrm{G}) \mathrm{VC}$ as a whole or information only specifically on the transport emissions-related aspects of products and their distribution.

Because only information would be required and no absolute prohibitions or maximum levels of emissions would be set, the effect of the instrument requiring mandatory disclosure of transport-related emissions would wholly rely on the market. Some consumers, not all, would take this information into account when making product choices, which in turn could be enough to make reality of what the Commission is hoping for. It could create market-led change in the industry or it would at least meet the objective of helping consumers choose (more) sustainable products and services - presuming they wish to do so. ${ }^{62}$

\footnotetext{
${ }^{61}$ The Commission is not unaware of this need, see Guidance for the development of Product Environmental Footprint Category Rules (PEFCRs), <http://ec.europ.eu/environment/eussd/smgp/ef_pilots.htm〉, accessed 5 May 2018.

${ }^{62} \operatorname{COM}(2015) 614$ final (n 2).
} 